http://www.banglajol.info/index.php/JBS/index

\title{
A NEW SPECIES OF TORYMUS DALMAN (HYMENOPTERA: TORYMIDAE) FROM INDIA WITH A CHECK LIST OF TORYMUS SPECIES OF INDIA AND ADJACENT COUNTRIES
}

\author{
T C Narendran, Nakeer Razak* \\ Department of Zoology, University of Calicut, Kerala, India- 673635
}

The genus Torymus Dalman is represented by 10 species in the Indian subcontinent which include India, Sri Lanka, Nepal, Bhutan, Bangladesh, Myanmar and Pakistan. Mani (1989), Narendran (1994), Sureshan and Narendran (2002) and Narendran et al. (2005) contributed to the study of Torymidae of this region. Narendran and Kumar (2005) compared Torymus indicus with Torymus kovaci Narendan \& Girish Kumar from Malaysia. Grissell (1994) included Indian species also in his book on world Torymidae. Graham and Gigsvijt (1998) revised the taxonomy of European species of Torymus. In this paper we describe another new species of Torymus from Kashmir (India). An up-to-date check list of species of India and adjacent countries are also included. The holotype of the new species is deposited in the Western Ghat Regional Station of the Zoological Survey of India, Kozhikode (ZSIK).

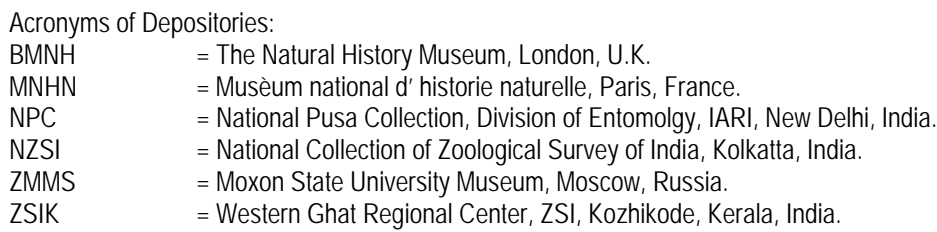

Torymus barsulicus Narendran \& Razak sp.nov.

Holotype: Female: Length (excluding ovipositor sheath) $3.6 \mathrm{~mm}$, length of ovipositor sheath $3.8 \mathrm{~mm}$ (Figs.1-5) .Colour: Antenna black with metallic green refringence on pedicel and scape, base of scape slightly paler; head, dorsum of mesosoma bright metallic green; sides of mesosoma and gaster dark metallic green; all coxae concolorous with sides of mesosoma; all femora dark metallic green with apex pale yellow; all tibiae pale yellow with a black spot on outer distal half on hind tibia; all tarsi of fore and mid legs and first four tarsi of hind leg pale yellow; fifth tarsal segment of hind leg and all pretarsi dark brown; wings hyaline with veins pale hyaline yellow.

Head: in dorsal view 2.42x as broad as long; temples $0.4 \mathrm{x}$ length of eye; POL 2.2 to $2.5 \mathrm{x} \mathrm{OOL}$; OOL $1.5 \mathrm{x}$ $\mathrm{OD}$; vertex with raised reticulation. Fontally seen mouth $2 x$ malar space, the latter $0.4 x$ length of eye; head width in anterior view $1.15 \mathrm{x}$ its height; eyes bare; frons and vertex raised reticulate and densely pilose; antennal toruli situated a little above level of ventral margin of eyes, a little nearer to clypeus than to anterior ocellus; pdicellus plus

Flagellum as long as breadth of head; relative L:W of antennal segments: scape $=28: 7$; pedicel= 9:7; F1= 9:9; F2= 7:10; F3= 8:10; F4= 8:10; F5= 8:10; F6= 8:10; F7= 8:10; clava= 22:10; sesillae numerous.

Mesosoma: 1.53x as long as broad (excluding tegulae), a little arched; notauli deep; mesoscutum 1.36x as broad as long, with raised reticulations, moderately pubescent; scutellum as long as broad, with rounded posterior margin; sculpture of scutellum as in mesoscutum; dorsellum not visible from dorsal view (scutellum

* Corresponding author E-mail: nakeer_razak@yahoo.com 
jutting over dorsellum); propodeum reticulate, spiracle separated from metanotum by a distance subequal to diameter of spiracle; hind femur 3.5x as long as broad; hind coxa 1.9x as long as broad, with somewhat coarsed, slightly raised reticulations. Forewing $2.5 \mathrm{x}$ as long as broad; speculum open behind; relative length of forewing veins: $\mathrm{SMV}=47 ; \mathrm{MV}=25 ; \mathrm{PMV}=13 ; \mathrm{STV}=6$.

Gaster: Gaster not compressed, T1 not extending to middle of coxal level; hypopygium extending middle of gaster; gaster (excluding ovipositor sheath) longer than mesosoma; ovipositor sheath 2.1x as long as gaster, a little longer than head plus mesosoma.

\section{Male: Unknown.}

Comments: This new species comes to Torymus arundinis (Walker) in the key to species by Graham and Gijswijt (1998) but differs from it in having: 1) POL 2.2x- 2.5x OOL (in T. arundinis POL 1.5-n1.6x as long as $\mathrm{OOL}$ ); 2) hind tibia pale yellow with a dark spot on either side (hind tibia without any spots); 3) forewing lower surface without any row of setae below cubital line; ( forewing lower surface with a double or triple row of setae below the cubital vein in $T$. arundinis); 4) mesosomal notum with raised reticulations (in $T$. arundinis mesosomal notum nearly always with less dense reticulation, most often with distinct piliferous punctures) and 5) length of longest spur of hind tibia more than one third that of hind basitarsus (in $T$. arundinis longest spur of hind tibia hardly one- third that of basitarsus.

In the key to species of Torymus of Indian subcontinent by Narendran et al. (2005) this new species come to Torymus nepalensis Narendran but differs from that species in having: 1) frenum reticulate and not delimited (in T. nepalensis) frenum delimited and smooth); 2) propodeum reticulate (in $T$. nepalensis propodeum smooth and shiny; 3) MV about 2x as long as PMV (in T. nepalensis) MV about 4x as long as PMV).

Material examined: Holotype, Female:INDIA, Kashmir, Barzulla, June 2008. Coll. Razak (ZSIK).

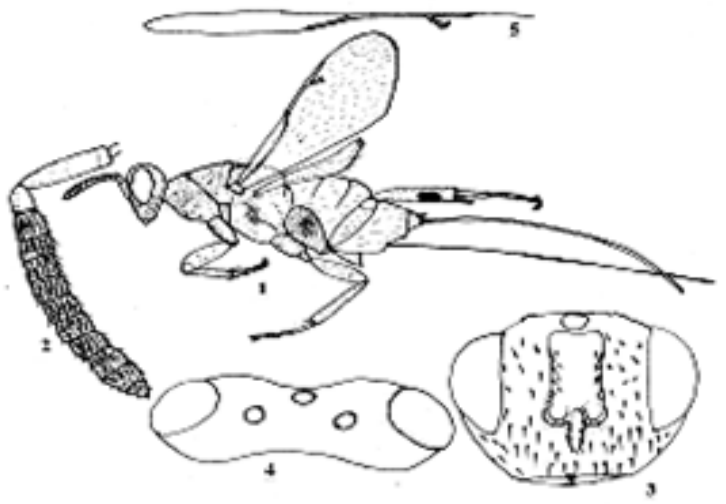

Figs. 1. Torymus barsulicus Narendran \& Razak sp. nov. Female: 1) Body Profile; 2) Antenna; 3) Head anterior view; 4) Head dorsal view; 5) Forewing veins.

Torymus absonus Narendran \& Girish Kumar

Torymus absonus Narendran \& Girish Kumar in Narendran Girish Kumar, Sudheer, Sureshan \& Chakrabarti, 2005. B 117. Holotype Female, India (ZSIK).

Host: Finger galls on leaf of Oak trees.

Distribution: India (Himachal Pradesh, Shogi).

Torymus barsulicus Narendran \& Razak sp. nov. 
Torymus barsulicus Narendran \& Razak, 2010 :1;. Holotype Female, India (ZSIK).

Host: Unknown.

Distribution: India (Kashmir, Barsula).

Torymus calcaratus Nees

Torymus calcaratus Nees, 1834: 69, Male (According to Graham \& Giswijt, 1998, type presumed to be lost).

Torymus igneiventris Costa, 1858: 27 (According to Graham \& Giswijt, 1998, type material not traced) (synonymized by Hoffmeyer, 1930).

Diomorus violaceus Kieffer, 1898: 123. Female, Italy (Depository unknown) (synonymy suggested by Masi 1919, synonymized by Hoffmeyer 1930).

Diomorus fertoni, Kieffer, 1898: 123- 124. Holotype Male, France (MNHN) (synonymized by Masi 1919).

Host: Reared from Sphecidae (Hymenoptera) in Rubus stems in Oak galls (Graham \& Gijswijt, 1998).

Distribution: Europe, Central Asia, India (Grisell, 1995; Narendran 1994).

Torymus chaubattiensis Bhatnagar

Torymus chaubattiensis Bhatnagar, 1951: 155. Holotype Female, India (Type probably lost. Host: Aphis helichrysi Kalf (Hymenoptera: Aphidoidea).

Distribution: India (Uttar Pradesh: Chaubattia).

Torymus cupreus (Spinola)

Diplolepis cuprea Spiola, 1808: 212- 213. Female, Italy (Depository unknown). Torymus cupreus Nees, 1834: 67, 69. Original material lost (Graham and Gijswijt, 1998).

Diomorus kollari Foerster, 1859: 102. Female, Austria (Depository unknown) (synonymized by Steffan, 1952).

Host: Parasite of Sphecidae and Apidae (Hymenoptera) (Graham \& Gijswijt, 1998).

Distribution: Europe, Central Asia, Mianmar (= Burma) (Grissell, 1994, Mani \& Kaul, 1972).

Torymus himachalicus Narendran \& Sureshan

Torymus himachalicus Narendran \& Sureshan in Narendran, Kumar, Sudheer, Sureshan \& Chakrabarti 30: 111- 121. India(Himachal Pradesh (ZSIK).

Host: Round gall on leaf of Oak trees.

Distribution: India (Himachal Pradesh).

Torymus indicus Ahmad

Diomorus indicus Ahmad 1946: 6- 7. Holotype Female, India (Bihar) (NPC).

Torymus indicus Ahmad: Narendran \& Girish Kumar, 2004.

Host: Larva in Poinciena pulcherima Stom Fabaceae.

Distribution: India (Bihar).

Torymus neepalensis Narendran

Torymus neepalensis Narendran: 1994: 21- 22. Nepal (BMNH).

Host: Unknown.

Distribution: Nepal.

Torymus orissaensis (Mani)

Lioterphus orissaensis Mani, 1936: 126. Holotype Female, India (Puri [Orissa] NZSI).

Torymus orissaensis (Mani): Narendran. 1994 transferred to Torymus.

Host: Unknown.

Distribution: India (Orissa). 
Torymus sharmai Sureshan \& Narendran

Torymus sharmai Sureshan \& Narendran, 2002: 867- 868. Holotype Female, India

(ZSIK).

Host: Reared from galls of Strobilanthus sessilis (Nees) (Acanthaceae) caused by an unnamed Cecidomyiid (Diptera) probably parasitic on it. (Sureshan \& Narendran, 2002).

Distribution: India (kerala).

\section{Torymus stom Narendan \& Sudheer}

Torymus stom Narendan \& Sudheer in Narendran, Kumar, Sudheer, Sureshan \&

Chakrabarti 2005: 115- 117. Female, India (ZSIK).

Host: Round gall on leaf of Oak trees.

Distribution: India (Himachal Pradesh).

Acknowledgements: T C N acknowledges Dr N Ramani, Head of the Department of Zoology, University of Calicut and Dr M Nasser Asst. Professor of the same department for facilities to carry out this research. N R acknowledges Dr Irfan Ahmad Asstt. Professor (SKUAST-Kashmir) for help in field.

\section{References}

Bhatnagar SP. 1951. Descriptions of new and rcordsof known Chalcidoidea (Parasitic Hymenoptera) from India. Indian J Agri Sci 21, 155- 178.

Costa A. 1858. Ricerche entologiche sopra I Monti Partenii. Napoli. Vico Freddo Pignasecea 29 pp.

Dalman JW. 1820. Försök till uppstallning of insect- familgen Pteromalini (Cynipae Ltr.), i synnerhet med afseende pa de I Sverige funne Arter- K. Svenska Vetensk akad H and I 41, 123- 174, 177- 182.

Foerster A. 1859. Zweite Centurie neuer hymenopteran. Verhandlungen des Naturhistorischen Vereins der Preussischen Rheinlande und Westfalous 16: 87- 124.

Graham MWR, de Vere and Gijswijt MJ. 1998. Revision of the European species of Torynus Dalman (S. lat.) (Hymenoptera: Torymidae) Zoologische Verhandalinger, Leidon 317, 1- 202.

Grissell EE. 1995. Toryminae (Hymenoptera: Chalcidoidea: Torymidae). A redefinition, generic classification and annotated world catalogue of species. Memoirs on Entomolgy International 2, $470 \mathrm{pp}$.

Hoffmeyer EB. 1929. Beitrage zur Kenntnis der danischen Callimomiden, mit Bestimmungstabellen der europaischen Arten (Hym. Chalc.) Entomologiske Meddelelser 17, 232- 260.

Kieffer JJ. 1898. Description de deusc nouveaux Torymides (Hymen.). Bull Soc Entomol Fr 1898, 123- 124.

Mani MS. 1936. Calcids from India. Records of Iu Indian Museum (Calcutta) 38: 125- 129.

Mani, M.S. 1989. The fauna of India and adjacent countries: Chalcidoidea (Hymenoptera). Pt. I and II, Madras, India: Zoological Survey of India. 1633 pp.

Mani MS, Kaul BK. 1972. Some Torymidae (Hymenoptera: Chalcidoidea) from India. Oriental Insects 6, 313- 331.

Masi L. 1919. Note Sui Calcididi raccolti in Liguria. Annali del Museo Civico di Storia Naturale di Genova 48, 121- 171.

Narendran TC. 1994. Torymidae and Eurytomidae of Indian Subcontinent, Zoological Monograph, University of Calicut. 500 pp.

Narendran TC, Kumar GP. 2005. A new species of Torymus Dalman (Hymenoptera: Torymidae) from West Malaysia, Zoos' Print J 20 (3), 1805- 1806.

Narendran TC, Kumar GP, Sudheer K, Sureshan PM, Chakrabarti S. 2005. Three new species of Torymus Dalman (Hymenoptera: Torymidae) from Himachal Pradesh (India) along with a key to species of Indian Subcontinent. Entomon 30 (2), 111- 121.

Nee sab Esenbeck CG. 1834. Hymenopterorum Ichneumonibus affinium monographiae genera Europae et species ilustrantes. Vol. 2. Stuttgrat and Tubinger: JG. Cottae. $448 \mathrm{pp}$.

Spinola M. 1808. Insectorum Liguriae species novae aut rariors. Vol. 2. Fax. 4: 209- 262. Genoa: A. Koenig

Sureshan PM, Narendran TC. 2002. Two new species of Torymidae (Hymenoptera: Chalcidoidea) from India. Zoos' Print J 17 (9) 67- 870 